Piotr Pragacz (Warszawa)

\title{
Notes on the life and work of Józef Maria Hoene-Wroński*
}

\begin{abstract}
This article is about Hoene-Wroński (1776-1853), one of the most original figures in the history of science. It was written on the basis of two talks delivered by the author during the session of Impanga "A tribute to Józef Hoene-Wroński" ${ }^{1}$, which took place on January 12 and 13, 2007 in the Institute of Mathematics of the Polish Academy of Sciences in Warsaw.
\end{abstract}

To reach the source, one has to swim against the current.

Stanisław J. Lec

1. Introduction and a short biography. This article is about Józef Maria Hoene-Wroński. He was - primarily - an uncompromising searcher of truth in science. He was also a very original philosopher. Finally, he was an extremely hard worker.

When reading various texts about his life and work and trying to understand this human being, I couldn't help recalling the following motto:

Learn from great people great things which they have taught us. Their weaknesses are of secondary importance.

\section{A short biography of Józef Maria Hoene-Wroński:}

1776

1794

$1795-1797$

$1797-1800$

1800

1803

1810

1853
- born on August 23 in Wolsztyn;

— joins the Polish army;

- serves in the Russian army;

- studies in Germany;

- comes to France and joins the Polish Legions in Marseilles;

- publishes his first work Critical philosophy of Kant;

- marries V. H. Sarrazin de Montferrier;

— dies on August 9 in Neuilly near Paris.

\footnotetext{
*Translated by Jan Spaliński. This paper was originally published in the Polish journal Wiadomości Matematyczne (Ann. Soc. Math. Pol.) vol. 43 (2007). We thank the Editors of this journal for permission to reprint the paper.

${ }^{1}$ Impanga is the name of a group working on algebraic geometry and algebra since 2000 in the Institute of Mathematics of the Polish Academy of Sciences. During the session mentioned above lectures were presented by: R. Murawski: The philosophy of Hoene-Wronski, T. Maszczyk: The highest Law of H-W, W. Karkucińska: The legacy of $H$ - $W$ in the Kórnik Library, W. Więsław: Mathematics at the time of $H$ - $W$, P. Domański: The work of Banach on the highest Law of $H$-W, W. Wójcik: The mathematics reform of $H-W$ and P. Pragacz: The life of $H-W$ and $H$-W's contributions to algebra.
} 
One could say that the starting point of the present article is chapter XII in [6]. I read this article a long time ago, and even though I read a number of other publications about Hoene-Wroński, the content of this chapter remained present in my mind due to its balanced judgments. Here we will be mostly interested in the mathematics of Wroński, and especially in his contributions to algebra and analysis. Therefore, we shall only give the main facts from his life - the reader may find more details in [9]. Regarding philosophy, we shall restrict our attention to the most important contributions - more information can be found in [36], [37], [47], and [10]. Finally, Wroński's most important technical inventions are only mentioned here, without giving any details.

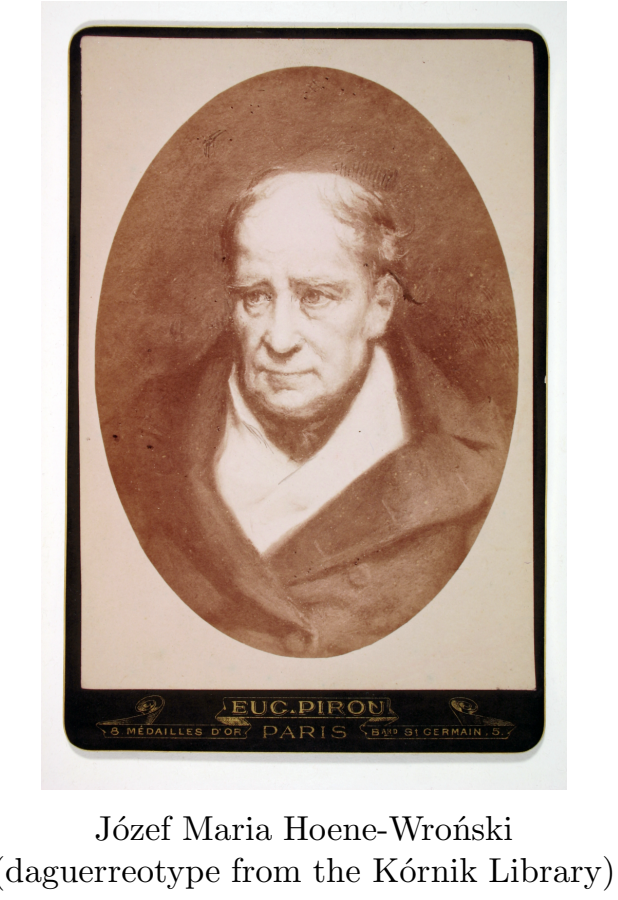

2. Early years in Poland. Józef Hoene was born in Wolsztyn on August $23^{2} 1776$. His father, Antoni, was a Czech emigrant and a well known architect. A year later the family moved to Poznań, where the father of the future philosopher became a famous builder (in 1779 Stanisław August the last King of Poland - gave him the title of the royal architect). In the years 1786-1790 Józef attended school in Poznań. Influenced by the political events of the time, he decided to join the army. His father's opposition was great, but the boy's determination was even greater. (Determination is

\footnotetext{
${ }^{2}$ Various sources give the 20 and the 24 of August.
} 
certainly the key characteristic of Wroński's nature.) In 1792 he run away from home and changed his name, to make his father's search more difficult. From that time on he was called Józef Wroński and under that name he was drafted by the artillery corps. In the uprising of 1794 he was noted for his bravery, and was quickly promoted. During the defense of Warsaw against the Prussian army he commanded a battery — and was awarded a medal by commander in chief Tadeusz Kościuszko for his actions. He also took part in the battle near Maciejowice, during which he was taken to captivity. At that time he made the decision to join the Russian army. What was the reason for such a decision we do not know; while consulting various materials on the life of Wroński, I haven't found a trace of an explanation. Maybe - this is just a guess - he counted on the possibility of gaining an education in Russia: Wroński's main desire was a deep understanding of the laws of science, and these are universal: the same in Russia as elsewhere ... A After being promoted to the rank of captain, he became an advisor of the General Staff of Suworow. In the years 1795-1797 he serves in the Russian army and is promoted to the rank of lieutenant-colonel.

3. Departure from Poland. The information about the sudden death of his father changed Wroński's plans. He inherited a large sum, which allowed him to devote himself to his studies, as he wanted for a long time. He quit the army and travelled West. Greatly inspired by Kant's philosophy, he arrived at Königsberg. However, when he found out that Kant is no longer giving lectures, Wroński left for Halle and Göttingen. In 1800 he visited England, and afterwards came to France. Fascinated by Dąbrowski's Legions, he asked the general for permission to join them. Dąbrowski agreed (however he did not honor the rank Wroński gained in Tzar's army) and sent him to Marseilles. There, Wroński could combine his service with his love for science. He became a member of Marseilles' Academy of Science and Marseilles' Medical Society.

In Marseilles Wroński underwent an enlightenment. This turning point in his life was a vision, which he had on August 15, 1803 at a ball on Napoleon's birthday. As he had described it, he had a feeling of anxiety and of certainty, that he would discover the "essence of the Absolute". Later he held that he understood the mystery of the beginning of the universe and the laws which govern it. From that time on he decided to reform human thought and create a universal philosophical system. In remembrance of that day he took the name of Maria and went down in history of science as Józef Maria Hoene-Wroński. Wroński's reform of human knowledge was to be based on a deep reform of mathematics by discovering its fundamental 
laws and methods. At the same time he posed the problem of solving the following three key issues in (applied) mathematics:

1. Discovering the relation between matter and energy (note Wroński's incredibly deep insight here);

2. the formation of celestial objects;

3. the formation of the universe from the celestial objects.

The most visible characteristic of Wroński's work is his determination to base all knowledge on philosophy, by finding the general principle, from which all other knowledge would follow.

Resources needed to publish papers have quickly run out, and Wroński started to support himself by giving private lessons of mathematics. Among his students was Victoria Henriette Sarrazin de Montferrier. The teacher liked this student so much, that in 1810 she became his wife. In September of the same year Wroński heads for the conquest of Paris.

4. Paris: solving equations, algorithms, continued fractions and struggles with the Academy. In 1811 Wroński publishes Philosophy of Mathematics [14] (see also [24]). Even earlier he has singled out two aspects of mathematical endeavor:

1. theories, whose aim is the study of the essence of mathematical notions;

2. algorithmic techniques, which comprise all methods leading to the computation of mathematical unknowns.

The second point above shows that Wroński was a pioneer of "algorithmic" thinking in mathematics. He gave many clever algorithms for solving important mathematical problems.

In 1812 Wroński publishes an article about solving equations of all degrees [15] (see also [20]). It seems that, without this paper, Wroński's scientific position would be clearer. In this paper Wroński holds that he has found algebraic methods to find solutions of equations of arbitrary degree. However, since 1799 it has been believed that Ruffini has proved the impossibility of solving equations of degree greater than 4 by radicals (Ruffini's proof - considered as essentially correct nowadays - at that time has lead to controversy ${ }^{3}$ and the mathematical community has accepted this

\footnotetext{
${ }^{3}$ Ruffini published his results in a book and in 1801 sent a copy to Lagrange, however he did not receive any response. Legendre and other members of the Paris Academy did not consider this work as worthy of attention. Only in 1821 - a year before his death - Ruffini received a letter from Cauchy who wrote that he considers Ruffini's result as very important.
} 
result only after Abel has published it in 1824). So did Wroński question the Ruffini-Abel theorem? Or did he not know it? As much as in the later years Wroński really did not systematically study the mathematical literature, in the first decade of the nineteenth century he has kept track of the major contributions. If one studies carefully the (difficult to understand) deliberations and calculations, it seems that, Wroński's method leads to approximate solutions, in which the error can be made arbitrarily small ${ }^{4}$. In his arguments besides algebraic methods, we find analytic and transcendental ones. This is the nature, for example, of his solution of the factorization problem coming from the work cited above, which we describe below. This type of approach is not quite original, it has been used by Newton for example $^{5}$. Since Wroński considered this work so important (it was reprinted again towards the end of 1840) — in order to gain a true picture of the situation - it would be better to publish a new version with appropriate comments of someone competent, explaining what Wroński does and what he does not do.

I think that such a competent person could have been Alain Lascoux, who, reading this and other works of Wroński, could see, that he was addressing the following three algebraic problems, connected with polynomials of one variable and Euclid's algorithm for such polynomials:

1. Consider two normed polynomials $F(x)$ and $G(x)$. Suppose that $\operatorname{deg}(F) \geqslant \operatorname{deg}(G)$. Performing multiple division of $F(x)$ and $G(x)$ :

$$
F=* G+c_{1} R_{1}, \quad G=* R_{1}+c_{2} R_{2}, \quad R_{1}=* R_{2}+c_{3} R_{3}, \quad \ldots .
$$

Successive coefficients " $*$ " are uniquely determined polynomials of the variable $x$ such that

$$
\operatorname{deg} G(x)>\operatorname{deg} R_{1}(x)>\operatorname{deg} R_{2}(x)>\operatorname{deg} R_{3}(x)>\ldots .
$$

Instead of the "ordinary" Euclid's algorithm, were $c_{1}=c_{2}=c_{3}=\ldots=1$ and where $R_{i}(x)$ are rational functions of the variable $x$ and roots of $F(x)$ and $G(x)$, one can choose $c_{i}$ in such a way that the successive remainders $R_{i}(x)$ are polynomials of the variable $x$ and of those roots. These remainders are called normed polynomial remainders or subresultants. Wroński constructed a clever algorithm for finding $R_{i}(x)$ (see [28], [29], [30]). Note that J. J. Sylvester has found other formulas for these remainders in [43] — although their validity has been established only very recently, see [31].

\footnotetext{
${ }^{4}$ It is interesting that the authors of [6] have reached a similar opinion, but without further details.

${ }^{5}$ Methods of Newton-Raphson and Laguerre are known.
} 
2. Using the algorithm in 1. and passing to the limit, Wroński [15] (see also [20]) also solved the following important factorization problem:

Suppose that we are given a normed polynomial $W(x) \in \mathbb{C}[x]$, which does not have roots of absolute value 1 . Let

$$
A:=\{a \in \mathbb{C}: W(a)=0,|a|>1\}, \quad B:=\{b \in \mathbb{C}: W(b)=0,|b|<1\} .
$$

Extract a factor $\prod_{b \in B}(x-b)$ from $W(x)$.

We give - following Lascoux [29] — Wroński's solution in terms of the Schur functions (here we use the definitions and notation for the Schur functions from [29] and [30]). The coefficients of the polynomial $W(x)$, from which we wish to extract a factor corresponding to roots of absolute value smaller than 1 , are the elementary symmetric functions of $A \cup B$ - the sum of (multi)sets $A$ and $B$. Therefore the problem boils down to expressing elementary symmetric functions of the variable $B$, in terms of the Schur functions of $A \cup B$, denoted by $S_{J}(A+B)$. Let the cardinality of the (multi)set $A$ be equal to $m$. For $I \in \mathbb{N}^{m}$ i $k, p \in \mathbb{N}$ we define

$$
I(k):=\left(i_{1}+k, \ldots, i_{m}+k\right), \quad 1^{p} I(k):=\left(1, \ldots, 1, i_{1}+k, \ldots, i_{m}+k\right)
$$

(where 1 is present $p$ times). Let the cardinality of the (multi)set $B$ be equal $n$. Wroński's theorem (in Lascoux's interpretation [29]) states that

$$
\prod_{b \in B}(x-b)=\lim _{k \rightarrow \infty}\left(\sum_{0 \leqslant p \leqslant n}(-1)^{p} x^{n-p} \frac{S_{1^{p} I(k)}(A+B)}{S_{I(k)}(A+B)}\right)
$$

(here $I$ is an arbitrary sequence in $\mathbb{N}^{m}$ ). Notice that the solution uses a passage to the limit; therefore besides algebraic arguments, transcendental arguments are also used. One can find the proof of this result in [29]. Therefore, we see that Wronski, looking for roots of algebraic equation, did not limit himself to using radicals.

3. Assuming that $\operatorname{deg}(F)=\operatorname{deg}(G)+1$, Wroński also found interesting formulas for the remainders $R_{i}(x)$ in terms of continued fractions (see [30], where his formulas are also expressed in terms of the Schur functions).

We note that Wronski also used symmetric functions of the variables $x_{1}, x_{2}, \ldots$, and especially the aleph functions. 


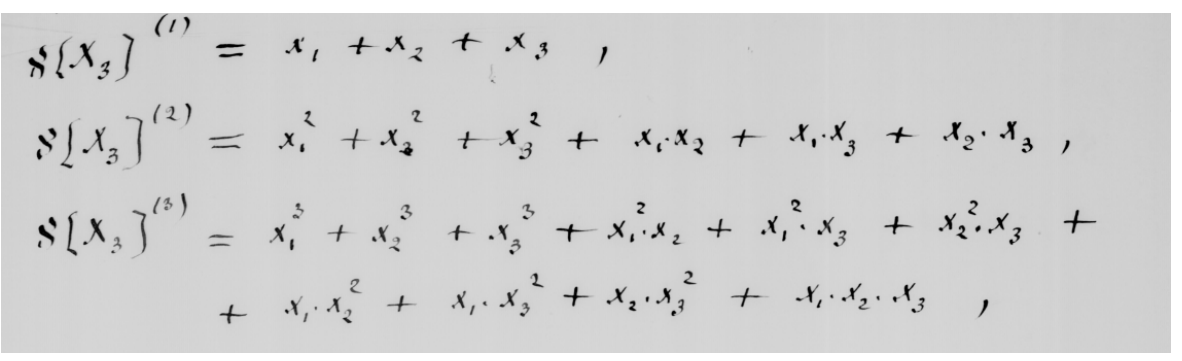

The aleph functions in three variables of degree 1,2 and 3 from Wroński's manuscript

More generally, for $n \in \mathbb{N}$ we let $X_{n}=\left\{x_{1}, \ldots, x_{n}\right\}$ and define functions $\aleph\left[X_{n}\right]^{i}$ by the formula

$$
\sum_{i \geqslant 0} \aleph\left[X_{n}\right]^{i}=\prod_{j=1}^{n}\left(1-x_{j}\right)^{-1},
$$

i.e. $\aleph\left[X_{n}\right]^{i}$ is the sum of all monomials of degree $i$. Wroński considered these functions as "more important" than the "popular" elementary symmetric functions. This intuition of Wroński has gained - let's call it - justification in the theory of symmetrization operators [30] — in the theory of Gröbner bases - so important in computer algebra (see e.g. [39]), as well as in the modern intersection theory in algebraic geometry [11], using rather Segre classes, which correspond to aleph functions, than Chern classes, corresponding to elementary symmetric polynomials. Here we quote one of the main creators of intersection theory - W. Fulton [11], p. 47:

Segre classes for normal cones have other remarkable properties not shared by Chern classes.

All this shows that Wroński had an unusually deep intuition regarding mathematics.

In Wroński's time there was a fascination with continued fractions ${ }^{6}$. As much as the earlier generations of mathematicians (Bombelli, Cataldi,

\footnotetext{
${ }^{6}$ The history of continued fractions is described in [4]. The nineteenth century can be described - without exaggeration - as the golden age of continued fractions. This was the time when this topic was known to every mathematician. The following are among those who were seriously involved: Jacobi, Perron, Hermite, Gauss, Cauchy and Stieltjes. Mathematicians studied continued fractions involving functions as well as those involving numbers (the same remark applies to the previous century, especially regarding the activity of Euler and Lambert). However it was Wroński who was the pioneer of functional continued fractions in interpolation theory - this fact, surprisingly, was noticed for the first time only recently by Lascoux [30].
} 
Wallis, Huygens, Euler, Lambert, Lagrange ... ) were interested mainly in expressing irrational numbers as continued fractions, obtaining such spectacular results as:

$$
\begin{aligned}
& \sqrt{2}=1+\frac{1}{2+\frac{1}{2+\frac{1}{2+\frac{1}{\ddots}}}}, \quad e=2+\frac{1}{1+\frac{1}{2+\frac{2}{3+\frac{3}{\ddots}}}}, \\
& \pi=3+\frac{1}{6+\frac{3^{2}}{6+\frac{5^{2}}{6+\frac{7^{2}}{\ddots}}}}
\end{aligned}
$$

— in Wroński's time attempts were made mainly to express functions of one variable as continued fractions. Already in Philosophy of Mathematics [14] from 1811 Wronski considered the problem of interpolation of a function of one variable $f(x)$ by continued fractions. Let $g(x)$ be an auxiliary function vanishing at 0 , and $\xi-$ an auxiliary parameter. Wroński gives the expansion of $f(x)$ as a continued fraction

$$
f(x)=c_{0}+\frac{g(x)}{c_{1}+\frac{g(x-\xi)}{c_{2}+\frac{g(x-2 \xi)}{c_{3}+\frac{g(x-3 \xi)}{\ddots}}}}
$$

expressing unknown parameters $c_{0}, c_{1}, c_{2}, \ldots$ in terms of $f(0), f(\xi)$, $f(2 \xi), \ldots$ This is connected with the Thiele continued fractions [44]. A few years later Wroński gave even more general continued fractions, considering instead of one auxiliary function $g(x)$ a system of functions $g_{0}(x), g_{1}(x), \ldots$, vanishing at various points:

$$
0=g_{0}\left(\alpha_{0}\right)=g_{1}\left(\alpha_{1}\right)=g_{2}\left(\alpha_{2}\right)=\ldots
$$

Wroński gives determinantal formulas $f\left(\alpha_{i}\right), i=0,1, \ldots$, for the coefficients $c_{j}, j=0,1, \ldots$, in the expansion

$$
f(x)=c_{0}+\frac{g_{0}(x)}{c_{1}+\frac{g_{1}(x)}{c_{2}+\frac{g_{2}(x)}{c_{3}+\frac{g_{3}(x)}{\ddots}}}} .
$$


These expansions are connected with the Stieltjes continued fractions [42] and play a key role in interpolation theory. In his book [30], Lascoux called them the Wronski continued fractions, therefore bringing Wroński's name for the second time (after Wrońskians) into the mathematical literature. More details, as well as specific references to Wroński's papers, can be found in [30].

In 1812 Wroński published Criticism of Lagrange's theory of analytic functions [16]. Wroński's views on this subject were shared by a number of other mathematicians, among others Poisson. The criticism regarded particularly the problem of interpretation of "infinitely small values" and the incomplete derivation of the Taylor formula. This is the paper where Wroński introduces for the first time "combinatorial sums" containing derivatives, today called Wronskians.

In these years Wroński searched for a solid foundation for his plans; he thought that he will find it in the most distinguished scientific institution: The French Academy. In 1810 he sent to the Academy — to establish contact - the article On the fundamental principles of algorithmic methods containing the "Highest Law", which allows expanding functions of one variable into a series ${ }^{7}$. The committee judging the article had established that Wroński's formula encompasses all expansions known until that time, the Taylor formula for example, but withheld confirming the validity of formula in its most general form. Wroński insisted on a definitive answer, and - in anticipation of a dispute - declined to accept the status of a Corresponding Member of the Academy suggested by Lagrange. The Academy did not give an official response neither to Wroński's reply, nor to his further letters. On top of that, such a serious work as the earlier mentioned Philosophy of Mathematics was not noticed by the Academy, as well as the article On solutions of equations. Of course, the attitude of the Academy with respect to Criticism of Lagrange's theory of analytic functions could not have been different and not hostile towards Wroński. In the committee judging the article was ... Lagrange himself and his colleagues. Because of the negative opinion, Wroński withdrew his paper from the Academy, directing - according to his character — bitter words towards the academics from Paris (phrases: "born enemies of truth", "les savants sur brevêts" are

\footnotetext{
${ }^{7}$ The name "The Highest Law" used to describe the possibility of expanding a function into a series may seem a bit pompous. We should remember, however, that mathematicians of that time were fascinated by the possibility of "passing to infinity". This fascination concerned not only infinite series, but also infinite continued fractions. Today there is nothing special about infinity: if a space needs to be compactified, one just "adds a point at infinity" ... . Wroński and his contemporaries treated infinity with great owe and respect as a great transcendental secret.
} 
among ... the milder ones).

At this time, Wroński's material situation has become much worse. While working on his publications, he has neglected his teaching, and the illness of his wife and child forced him to sell all of his possessions. Despite all efforts, the child could not be saved, and Wroński dressed in worn out clothes and clogs. He asked Napoleon himself for funding, however Napoleon was not interested in his activity. Wroński lived on the edge of the large Polish emigration in Paris, even though — as he bitterly states in his diaries - he dedicated his treatise on equations to his Polish homeland.

A (financially) important moment was Wroński's meeting with P. Arson, a wealthy merchant and banker from Nice, to whom Wroński was introduced by his old friend Ph. Girard (by the way, Girard was the founder of Żyrardów, a Polish town). Arson, fascinated by Wroński's ideas, promised to fund his activity for a few years. In return, Wroński was to reveal him the secret of the Absolute. This strange bond of a philosopher and a banker lasted until 1816 r. Arson, Wroński's secretary, finally insisted the revealing of the secret, and when the mentor did not do so, Arson took him to court. The matter become so well known, that after a few years it was the theme of one of Balzac's books The search for the Absolute. Arson resigned his post, but had to pay the debts of his ex-mentor (because Wronski won in court, by convincing the judge, that he knows the mystery of the Absolute). At that time Wroński publishes Le Sphinx, a journal which was to popularize his social doctrines.

The years 1814-1819 bring more Wroński's publications, mostly in the area of philosophy of mathematics: Philosophy of infinity (1814), Philosophy of algorithmic techniques (1815, 1816, 1817), Criticism of Laplace's generating functions. The Academy has neglected all these publications.

5. The stay in England. In 1820 Wroński went to England, in order to compete for an award in a contest for a method to measure distances in navigation. This trip was very unfortunate. On the boarder, the customs officials took possession of all his instruments, which Wronski never recovered. His papers were regarded as theoretical, and as such not suitable for the award. Finally, the secretary of the Board of Longitude, T. Young has made certain important modifications in the tables of his own authorship on the basis of Wroński's notes sent to him, "forgetting" to mention who should be given credit for these improvements. Of course, Wroński protested by sending a series of letters, also to the Royal Society. He had never received a response.

The very original Introduction to the lectures of mathematics [18] dates 
from this period (see also [22]), written in English and published in London in 1821. Wroński states there, that all positive knowledge is based on mathematics or in some sense draws from it. Wroński divides the development of mathematics into $4+1$ periods:

1. works of the scholars of East and Egypt: concrete mathematics was practiced, without the ability to raise to abstract concepts;

2. the period from Tales and Pythagoras until the Renaissance: the human mind rose to the level of high abstraction, however the discovered mathematical truths existed as unrelated facts, not connected by a general principle as e.g. the description of the properties of conic sections;

3. the activity of Tartaglia, Cardano, Ferrari, Cavalieri, Bombelli, Fermat, Vieta, Descartes, Kepler, ... : mathematics rose to the study of general laws thanks to algebra, but the achievements of mathematics are still "individual" - the "general" laws of mathematics were still unknown;

4. the discovery of differential and integral calculus by Newton and Leibniz, expansion of functions into series, continued fractions popularized by Euler, generating functions of Laplace, theory of analytic functions of Lagrange. The human mind was able to raise from the consideration of quantities themselves to the consideration of their creation in the calculus of functions, i.e. differential calculus.

The fifth period should begin with the discovery of the Highest Law and algorithmic techniques by Wroński ; the development of mathematics should be based on the most general principles — "absolute ones" - encompassing all of mathematics. This is because all the methods and theories up to that time do not exhaust the essence of mathematics, as they lack a general foundation, from which everything would follow. They are relative, even though science should look for absolute principles. Therefore, the fifth period foresees a generalization of mathematics. Indeed, this will happen later, but not on the basis of philosophy, as Wroński wanted. We mention here the following mathematical theories, which appeared soon: group theory (Galois), projective geometry (Monge, Poncelet), noneuclidean geometries (Łobaczewski, Bolyai, Gauss, Riemann) and set theory (Cantor).

6. Canons of logarithms - a bestseller. In 1823 Wroński is back in Paris and is working on mathematical tables and construction of mathematical instruments: an arithmetic ring (for multiplication and division) and "arithmoscope" (for various arithmetic operations). Among Wroński's achievements in this matter, is his Canon of logarithms [19] (see also [23]). With the help of appropriate logarithms and cleverly devised decomposi- 
tion of a number into certain parts, common for different numbers, he was able to set these parts in such a way, that these tables, even for very large numbers, fit onto one page. For logarithms with 4 decimal places the whole table can be fitted into a pocket notebook. Wroński's Canon of logarithms has been published many times in different languages (and shows that, besides very hard to read treatises, he could also produce works which are easier to comprehend).

In 1826 Wroński went to Belgium for a short time, where he was able to interest Belgian mathematicians in his achievements. In fact Belgian scientists were the first to bring Hoene-Wroński into worldwide scientific literature.

In 1829 Wroński, fascinated by the advances in technology, published a treatise on the steam engine.

7. Letters to the rulers of Europe. From around 1830 until the end of his life Wroński focused exclusively on the notion of messianism. At that time he published his well known Address to the Slavonic nations about the destiny of the World and his most well-known works: Messianism, Deliberations on messianism and Introduction to messianism. At that time he also sent memoranda to Pope Leon XII and the Tsars, so that they would back his messianistic concept.

One should also mention, that Wroński sent letters to the rulers of Europe instructing them how they should govern. These letters contained specific mathematical formulas, how to rule. Here is an example of such a formula from The Secret letter to his Majesty Prince Louis-Napoléon [21] from 1851.

Let $a$ be the degree of anarchy, $d$ - the degree of despotism. Then

$$
\begin{aligned}
& a=\left(\frac{m+n}{m} \cdot \frac{m+n}{n}\right)^{p-r} \cdot\left(\frac{m}{n}\right)^{p+r}=\left(\frac{m+n}{n}\right)^{2 p} \cdot\left(\frac{m}{m+n}\right)^{2 r}, \\
& d=\left(\frac{m+n}{m} \cdot \frac{m+n}{n}\right)^{r-p} \cdot\left(\frac{n}{m}\right)^{p+r}=\left(\frac{n}{m+n}\right)^{2 p} \cdot\left(\frac{m+n}{m}\right)^{2 r}
\end{aligned}
$$

where $m=$ number of members of the liberal party, $p=$ the deviation of the philosophy of the liberal party from true religion, $n=$ the number of members of the religious party, $r=$ the deviation of the religious party from true philosophy. According to Wroński, for France one should take $p=r=1$, and then

$$
a=\left(\frac{m}{n}\right)^{2}, \quad d=\left(\frac{n}{m}\right)^{2} .
$$

Moreover, $\frac{m}{n}=2$, and so $a=4, d=\frac{1}{4}$. This means that, political freedom 
- in France of Wronski's time - is four times the normal one, and the authority of the government is one quarter of what is essential.

(The application of the above formulas to the current Polish political reality would be interesting .... .)

8. Philosophy. I. Kant's philosophy was the starting point of the philosophy of Wroński, who has transformed it into metaphysics in a way analogous to Hegel's approach. Wroński has not only created a philosophical system, but also its applications to politics, history, economy, law, psychology, music (see [38]) and education. Existence and knowledge followed from the Absolute, which he understood either as God, or as the spirit, wisdom, a thing in itself. He did not describe it, but he tried to infer from it a universal law, which he called "The Law of Creation".

In his philosophy of history he predicted reconstruction of the political system, from one full of contradictions to a completely reasonable one. In the history of philosophy he distinguished four periods, each of which imposed on itself different aims:

1. east - material aims;

2. Greak-Roman - moral aims;

3. medieval - religious aims;

4. modern, until the XVIII century - intellectual aims.

He treated the XIX-th century as a transitional period, a time of competition of two blocs: conservative bloc whose aim is goodness and liberal bloc whose aim is the truth.

Wroński is the most distinguished Polish messianic philosopher. It is him (and not Mickiewicz nor Towiański) who introduced the notion of "messianism". Wroński held, that it is the vocation of the human race to establish a political system based on reason, in which the union of goodness and truth and religion and science will take place. The Messiah, who will bring the human race into the period of happiness, is - according to Wroński's concepts - precisely philosophy.

Jerzy Braun was an expert and promoter of Wroński's philosophy in Poland. His article Aperçu de la philosophie de Wroński published in 1967 is much valued by the French scholars of Wroński's philosophy.

9. Mathematics: The Highest Law, Wrońskians. Essentially, Wroński worked on mathematical analysis and algebra. We have already 
discussed Wroński's contributions to algebra. In analysis ${ }^{8}$ he was especially interested in expanding functions in a power series and differential equations. Wroński's most interesting mathematical idea was his general method of expanding a function $f(x)$ of one variable $x$ into a series

$$
f(x)=c_{1} g_{1}(x)+c_{2} g_{2}(x)+c_{3} g_{3}(x)+\ldots,
$$

when the sequence of functions $g_{1}(x), g_{2}(x), \ldots$ is given beforehand, and $c_{1}, c_{2}, \ldots$ are numerical coefficients to be determined. Notice that if

$$
g_{1}(x), g_{2}(x), \ldots
$$

form an orthonormal basis with respect to the standard, or any other, inner product $(\cdot, \cdot)$ on the (infinite dimensional) vector space of polynomials of one variable, then for each $i$ we have

$$
c_{i}=\left(f(x), g_{i}(x)\right) .
$$

However, such a simple situation rarely happens. Wroński gave his method of finding the coefficients $c_{i}$ the rank of The Highest Law. From today's point of view the method lacked precision and rigor (for example, Wroński did not consider the matter of convergence), however it contained - besides interesting calculations - useful ideas. These ideas were used much later by Stefan Banach, who formulated them precisely and enriched them with topological concepts, and proved that the Highest Law of Hoene-Wroński can be used in what is called today a Banach space, as well as in the theory of orthogonal polynomials. I will mention here a little known letter of Hugo Steinhaus to Zofia Pawlikowska-Brożek:

Maybe you will find the following fact concerning two Polish mathematicians - Hoene-Wronski and Banach - interesting. In Lwów we had an edition of Wronski's work published in Paris and Banach showed me the page written by the philosopher which discussed the "Highest Law"; apparently Banach has proven to me, that Wronski is not discussing messianic philosophy - the matter concerns expanding arbitrary functions into orthogonal ones (letter of 28.06.1969).

Banach presented a formal lecture on applying Wronski's Highest Law to functional analysis at a meeting in the Astronomic Institute in Warsaw, which was chaired by the well-known astronomer Tadeusz Banachiewicz. He also, as a young researcher, applied Wroński's results in one of his papers on

\footnotetext{
${ }^{8}$ Strictly speaking, making a distinction between algebra and analysis is not strictly correct, since Wroński often mixed algebraic and analytic methods.
} 
theoretical astronomy ${ }^{9}$. The content of Banach's lecture appeared in print as [2]. We note that S. Kaczmarz and H. Steinhaus in their book [26] on orthogonal polynomials published in 1936 have appealed for an explanation of Wroński's contribution to the theory of those polynomials.

By developing the method of the Highest Law, Hoene-Wroński found a way to compute the coefficients of a function series. In order to achieve this, as auxiliary objects, he used certain determinants, which Thomas Muir in 1882 called Wroński's determinants, or Wrońskians. At that time, Muir worked on a treatise on the theory of determinants [33]. Looking through Wroński's papers, and especially Criticism of Lagrange's theory of analytic functions [16], Muir noticed that Wroński in a pioneering way introduced and systematically used "combinatorial sums" ${ }^{10}$, denoted by the Hebrew letter Shin - in modern language called determinants - containing successive derivatives of the functions present:

$$
f g^{\prime}-f^{\prime} g, \quad f g^{\prime} h^{\prime \prime}+g h^{\prime} f^{\prime \prime}+h f^{\prime} g^{\prime \prime}-h g^{\prime} f^{\prime \prime}-f h^{\prime} g^{\prime \prime}-g f^{\prime} h^{\prime \prime}, \quad \ldots
$$

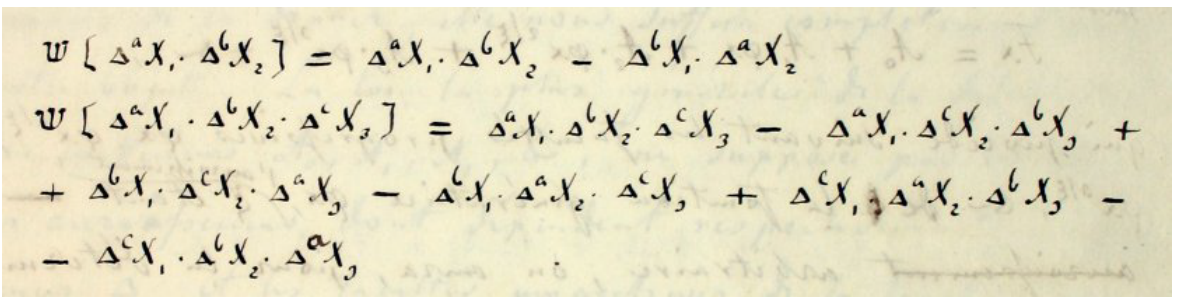

A fragment of page 11 of a manuscript of [16] with combinatorial sums

In modern notation the Wrońskian of $n$ real functions

$$
f_{1}(x), f_{2}(x), \ldots, f_{n}(x),
$$

\footnotetext{
${ }^{9} \mathrm{~T}$. Banachiewicz applied the ideas of Wroński's Highest Law in the calculus of the cracovians - see [3].

${ }^{10}$ In contemporary mathematics determinants are always associated with matrices both conceptually and in notation. Historically, they were introduced earlier than matrices "as sums with signs" and as such were used in computations, finding many interesting properties, which seem to be natural only when using the language of matrices (as, for example, the Binet-Cauchy's theorem). Matrices were introduced around 1840 by Cayley, Hamilton, ... , and Sylvester created in the 1850-ties a transparent calculus of determinants and minors based on the notion of a matrix (see e.g. [43]).
} 
which are $(n-1)$ times differentiable, is defined and denoted as follows:

$$
W\left(f_{1}, f_{2}, \ldots, f_{n}\right)=\left|\begin{array}{cccc}
f_{1} & f_{2} & \ldots & f_{n} \\
f_{1}^{\prime} & f_{2}^{\prime} & \ldots & f_{n}^{\prime} \\
f_{1}^{\prime \prime} & f_{2}^{\prime \prime} & \ldots & f_{n}^{\prime \prime} \\
\vdots & \vdots & \ddots & \vdots \\
f_{1}^{(n-1)} & f_{2}^{(n-1)} & \ldots & f_{n}^{(n-1)}
\end{array}\right|
$$

(there also exists a Wrońskian of a system of vector valued functions). Wrońskians are one of the basic tools in the theory of differential equations $([1],[40])$ and are so called in the mathematical literature from every part of the world. Probably, most often Wrońskians are used to test whether a sequence of functions is linearly independent:

Suppose that $f_{1}(x), \ldots, f_{n}(x)$ are $(n-1)$-fold differentiable functions. If $W\left(f_{1}, f_{2}, \ldots, f_{n}\right)$ is not identically zero, then the functions $f_{1}, \ldots, f_{n}$ are linearly independent ${ }^{11}$.

Properties and certain applications of Wrońskians were treated in [7]. The use of Wrońskians is not confined to analysis. In the classical reference work on the theory of invariants [13], the authors employ them in the algebraic theory of binary forms. Analogues of Wrońskians were constructed in other parts of mathematics. For example, Wrońskians of linear systems (Galbura [12], Laksov [27]), which are certain morphisms of vector bundles, are an important tool in modern algebraic geometry: they are used to the Plücker formulas in enumerative geometry and the theory of Weierstrass points. This pioneering invention, or maybe discovery of Wroński, is really very deep and lies at the heart of mathematics and proves Wroński's incredible feel for what is really important. In particular, Wroński used more general functional determinants than Wrońskians at the time when determinants of numerical matrices just begun to appear in the work of other mathematicians.

In physics, Wroński was interested in the theory of optical instruments and fluid mechanics. He improved steam engines, designed a mechanical calculator, created the concept of "moving rails", that is the contemporary caterpillar tracks, so once more he was ahead of his time for very many years.

\footnotetext{
${ }^{11}$ The reverse implication is - in general - not true.
} 
10. Wroński in the eyes of people in science and art. He was a genius in many respects, and had the ability to work very hard. In the over three hundred page biography of Wroński, Dickstein [9] writes:

His iron nature required little sleep and food, he begins work early in the morning and only after a couple of hours of work he would have a meal saying: "Now I have earned my day".

and then he adds:

The seriousness of his work and the struggle against misfortune did not spoil his calm personality and cheerful character.

Wroński wrote a very large number of papers in mathematics, philosophy, physics and technical science (see [25] and [8]).

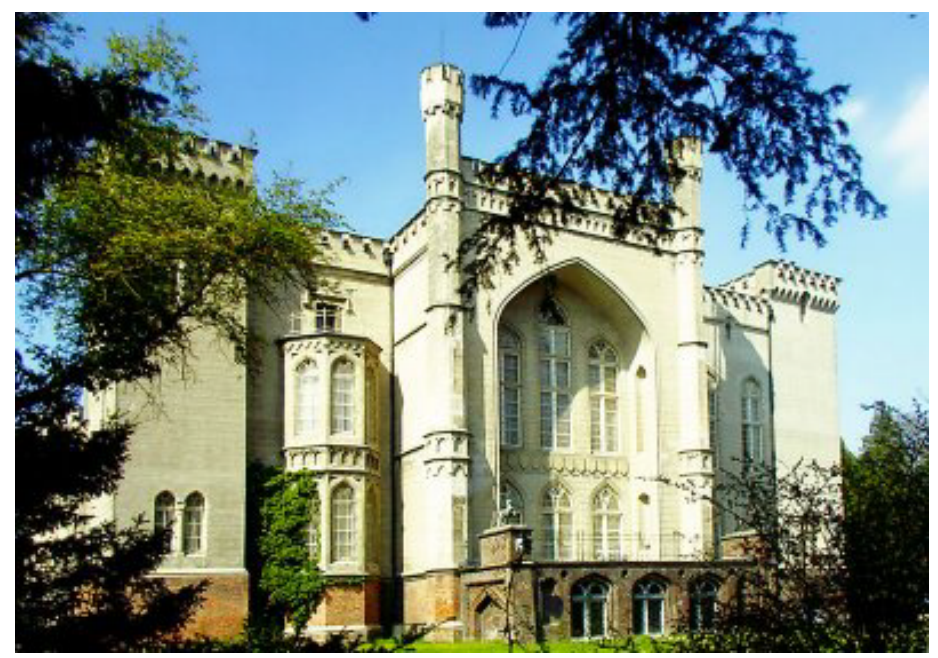

Palace in Kórnik near Poznań, containing a collection of Wroński's original handwritten manuscripts. They may contain interesting - unknown to the public yet - mathematical results (picture by Stanisław Nowak).

In 1875 the Kórnik Library purchased a collection of Wroński's books, articles and manuscripts [25] from Wroński's adopted daughter Bathilde Conseillant. After his death his friends (most notably Leonard Niedźwiecki the good spirit of the Polish Emigration and a close friend of Wroński) made an effort to publish Wroński's collected works (many were left in handwritten form). It has turned out, that his works would fill 10 volumes of about 800 pages each. Thirteen years after his death, the Polish Scientific Society in Paris, whose aim was bringing together all Polish scientists, organized a contest for the evaluation of Wroński's works. Amongst the reasons why 
only one work was submitted to the contest, and why Wroński's works besides a close circle of his "admirers" - were not very popular, is that they were very hard to read. This was the effect of aiming for the highest generality and of joining mathematical concepts with philosophical ones. Indeed, Wroński is not easy to read — he is a very demanding author. He was also very demanding during his life, first of all of himself, but also of others, and this did not win him friends, but rather made many enemies. It was a difficult character; in [9] we find:

He combined extreme simplicity in his home life with bold language and pride coming form a deep conviction about his historic mission, and the infallibility of his philosophy. He considered adversaries of his philosophy as enemies of the truth, and fought with them vehemently, often stating his arguments in a too personal way....

However, one should state clearly that during his life Wroński did not receive any constructive review and criticism, which — besides pointing out unclear passages in his work - would also pick out truly ingenious ideas (which were definitely present). The attitude of the French Academy does not give it credit. Wroński wrote bitterly about the academics of Paris:

These gentlemen are interested neither in progress nor in the truth ....

Well, Wroński was many years ahead of his period. Balzac described Wroński as "the most powerful mind of Europe". The well-known Polish writer Norwid had a similar opinion of Wroński (see [38], p. 30). Wroński's political visions "anticipated" the European union - a federation of countries in a united Europe, ruled by a common parliament. Dickstein is probably correct in writing:

Besides versatility, the dominating feature of Wronski's mind was, so to speak, architectural ability. He himself mentioned in one of his earliest works ("Ethic philosophy"), the most beautiful privilege of the human mind is the ability to construct systems.

Who knows whether in Germany Wroński would not have a better chance to find readers who would appreciate his works, written somewhat in "the style" of great German philosophers.

Wroński is - not only in the opinion of the author of this text - the most unappreciated great Polish scientist in his own country. It seems that he is much more appreciated abroad. And so, in the Museum of Science in Chicago, in a table with the names of the most prominent mathematicians in history, one can find the names of only three Polish mathematicians: Copernicus, Banach, and ... Hoene-Wroński. Also the rank of Wroński in 
XIX-th century philosophy is high. It seems that in France Wronski - the philosopher - is valued much more than in Poland (see e.g. [47] and [10]). The scientific legacy of such a great thinker as Wroński should be described in a comprehensive monograph in his homeland.

11. Non omnis moriar. Wroński's life was long and hard. Did any famous scientific authority - during his life — say a good word about what Wroński has achieved ${ }^{12}$ ? Still in 1853 Wroński writes two papers, and prepares a third one for publication: he studies the theory of tides. He sends the first two to the Navy Department. He received a reply saying that Laplace's formulas are completely sufficient for the needs of the navy. This was a severe blow for the 75-year old scientist who, after 50 years of hard work, once more has not found recognition. He died on August 9, 1853 in Neuilly. Before his death he whispered to his wife:

Lord Almighty, I had so much more to say.

Józef Maria Hoene-Wroński is buried at the old cemetery in Neuilly. The following words are written on his grave (in French):

\section{THE SEARCH OF TRUTH IS A TESTIMONY TO THE POSSIBILITY OF FINDING IT.}

After writing this article, I have realized that it has - in fact - a lot in common with my article about A. Grothendieck in the previous volume of Impanga Lecture Notes (Topics in cohomological studies of algebraic varieties, Trends in Mathematics, Birkhäuser, 2005). In his diaries Harvest and Sowing (vol. I, p. 94), Grothendieck wrote:

... one night ... I realized that the DESIRE to know and the POWER to know and to discover are one and the same thing.

\footnotetext{
${ }^{12}$ During Wroński's life two important works were published [41] and [32], citing his mathematical achievements. In [41], theorems and formulas of Wroński are given in a couple of dozen places, and in [32] his most important mathematical ideas are summarized. Despite of that, contemporary thinkers knew little of Wroński's achievements, and often reinvented what Wroński had discovered many years earlier.

About 20 years after Wroński's death, some notes about Wroński the mathematician and philosopher appeared in Poncelet's book Applications d'Analyse et de Géométrie, and also in the works of Cayley [5] and Transon [45], [46], which developed Wroński's ideas. One could say that Wrońskians "were firmly enrooted" in mathematics even before Muir coined the term. In the multi-volume history of determinants [34] and [35], works from the period 1838-1920 devoted to Wrońskians are summarized which have been written by: Liouville, Puiseaux, Christoffel, Sylvester, Frobenius, Torelli, Peano. Muir stresses there, that the interest in Wrońskians rose as time went by.
} 
Acknowledgements: I became fascinated with Hoene-Wroński thanks to Alain Lascoux - without this fascination this article could not have been written.

This text reached its final form after I have listened to the lectures and comments presented at the session of Impanga A tribute to Józef HoeneWronski described in the Introduction; I sincerely thank the speakers, as well as Jerzy Browkin and Maciej Skwarczyński. I also thank Jan Krzysztof Kowalski, Maria Pragacz and Jolanta Zaim for their help with the editorial process, as well as Wanda Karkucińska and Magdalena Marcinkowska from the Kórnik Library of the Polish Academy of Sciences for allowing me to publish the daguerreotype of Wroński and parts of his manuscripts, and also for their help in the work on those manuscripts.

Finally, I am grateful to Jan Spaliński for translating the text into English, and to Paolo Aluffi and Jacek Brodzki for their commments on an earlier version of this article.

\section{Bibliography}

[1] W. I. Arnold, Ordinary differential equations, Nauka, Moscow 1971 (in Russian).

[2] S. Banach, Über das "Loi suprême" von J. Hoene-Wroński, Bulletin International de l'Academie Polonaise des sciences et de lettres, Série A (1939), $450-457$.

[3] T. Banachiewicz, Rachunek krakowianowy z zastosowaniami, PAN, Komitet Astronomiczny, PWN, Warszawa 1959.

[4] C. Brezinski, History of continued fractions and Padé approximants, Springer, Berlin 1991.

[5] A. Cayley, On Wroński's theorem, Quart. J. Math. 12 (1873), 221-228.

[6] J. Dianni, A. Wachułka, Tysiac lat polskiej myśli matematycznej, PZWS, Warszawa 1963.

[7] S. Dickstein, Wtasności i niektóre zastosowania wronskianów, Prace Matematyczno-Fizyczne 1 (1888), 5-25.

[8] S. Dickstein, Katalog dzieł i rękopisów Hoene-Wrońskiego, nakładem Akademii Umiejętności, Kraków 1896; also in [9], pp. 239-351.

[9] S. Dickstein, Hoene-Wroński. Jego życie i prace, nakładem Akademii Umiejętności, Kraków 1896.

[10] J-C. Drouin, Les grands thèmes de la pensée messianique en France de Wroński à Esquiros: christianisme ou lä̈cisme?, in: Messianisme et slavophilie, Wyd. Uniw. Jagiell., Kraków 1987, 55-66. 
[11] W. Fulton, Intersection theory, Springer, Berlin 1984.

[12] G. Galbura, Il wronskiano di un sistema di sezioni di un fibrato vettoriale di rango i sopra una curva algebrica ed il relativo divisore di Brill-Severi, Ann. Mat. Pura Appl. 98 (1974), 349-355.

[13] J. H. Grace, A. Young, The algebra of invariants, Cambridge University Press, Cambridge 1903; there exists a reprint: Stechert \& Co., New York 1941.

[14] J. M. Hoene-Wroński, Introduction à la Philosophie des Mathématiques et Technie de l'Algorithmique, Courcier, Paris 1811.

[15] J. M. Hoene-Wroński, Résolution générale des équations de tous les degrés, Klostermann, Paris 1812.

[16] J. M. Hoene-Wroński, Réfutation de la théorie des fonctions analytiques de Lagrange, Blankenstein, Paris 1812.

[17] J. M. Hoene-Wroński, Philosophie de la technie algorithmique: Loi Suprême et universelle; Réforme des Mathématiques, Paris 1815-1817.

[18] J. M. Hoene-Wroński, A course of mathematics, Introduction determining the general state of mathematics, London 1821.

[19] J. M. Hoene-Wroński, Canons de logarithms, Didot, Paris 1824.

[20] J. M. Hoene-Wroński, Réforme absolue et par conséquent finale du Savoir Humain. Tome I: Réforme des Mathématiques; Tome III: Résolution générale et définitive des équations algébriques de tous les degrés, Didot, Paris 18471848.

[21] J. M. Hoene-Wroński, Epitre Secrète à son Altesse le Prince Louis-Napoléon, Dépôt des Ouvrages Messianiques, Metz 1851.

[22] J. M. Hoene-Wroński, Wstęp do wyktadu Matematyki, transl. from French by L. Niedźwiecki, Biblioteka Polska, Quais d'Orleans 6, Paris 1880.

[23] J. M. Hoene-Wroński, Kanony logarytmów, transl. from French by S. Dickstein, Warszawa 1890.

[24] J. M. Hoene-Wroński, Wstęp do Filozofii Matematyki oraz Technia Algorytmii, transl. from French by P. Chomicz, Prace Towarzystwa HoeneWrońskiego, Inst. Wyd. "Biblioteka Polska", Warszawa 1937.

[25] J. M. Hoene-Wroński, The legacy of Hoene-Wroński in the Kórnik Librarysee: www.bkpan.poznan.pl/biblioteka/index.html

[26] S. Kaczmarz, H. Steinhaus, Theorie der Orthogonalreihen, Warszawa-Lwów 1936.

[27] D. Laksov, Wronskians and Plücker formulas for linear systems on curves, Ann. Sci. École Norm. Sup. (4) 17 (1984), 45-66.

[28] A. Lascoux, Diviser!, in: M. Lothaire, Mots, Mélanges offerts à M.-P. Schützenberger, Hermès, Paris 1990. 
[29] A. Lascoux, Wroński's factorization of polynomials, in: Topics in Algebra, Banach Center Publ. 26, Part 2, PWN, Warszawa 1990, 379-386.

[30] A. Lascoux, Symmetric functions and combinatorial operators on polynomials, CBMS Regional Conf. Ser. in Math. 99, Amer. Math. Soc., Providence 2003.

[31] A. Lascoux, P. Pragacz, Double Sylvester sums for subresultants and multiSchur functions, J. Symbolic Comp. 35 (2003), 689-710.

[32] A. S. de Montferrier, Dictionnaire des sciences mathématiques pures et appliquées, Paris 1834-1840.

[33] T. Muir, A treatise on the theory of determinants, London 1882; there exists a reprint: Dover, New York 1960.

[34] T. Muir, The theory of determinants in the historical order development, 4 volumes, Macmillan \& Co., London 1906, 1911, 1920, 1923; there exists a reprint: Dover, New York 1960.

[35] T. Muir, Contributions to the history of determinants, 1900-1920, Blackie and Son, London, Glasgow 1930.

[36] R. Murawski, Józef Maria Hoene-Wroński - filozof i matematyk, Materiały konferencyjne Uniwersytetu Szczecińskiego, 30 (1998), 29-46.

[37] R. Murawski, Genius or madman? On the life and work of J. M. HoeneWroński, in: European mathematics in the last centuries (ed. W. Więsław), Wrocław 2005, 77-86.

[38] C. K. Norwid, O Szopenie, Fundacja Narodowego Wydania Dzieł Fryderyka Chopina, Łódź 1999.

[39] H. Ohsugi, T. Wada, Gröbner bases of Hilbert ideals of alternating groups, J. Symb. Comp. 41 (2006), 905-908.

[40] L. S. Pontrjagin, Ordinary differential equations, Mir, Moscow 1974 (in Russian).

[41] F. Schweins, Theorie der Differenzen und Differentiale, Heidelberg 1825.

[42] T. J. Stieltjes, Recherches sur les fractions continues, Ann. Fac. Sc. Toulouse 8 (1894), 1-122.

[43] J. J. Sylvester, A theory of the syzygetic relations of two rational integral functions, Phil. Trans. Royal Soc. London CXLIII, Part III (1853), 407-548.

[44] T. N. Thiele, Interpolationrechnung, Teubner, Leipzig 1909.

[45] A. Transon, Réflexions sur l'événement scientifique d'une formule publiée par Wroński en 1812 et démontrée par Cayley en 1873, Nouvelles Annales de mathématiques 13 (1874), 161-174.

[46] A. Transon, Lois des séries de Wroński. Sa phoronomie, Nouvelles Annales de mathématiques 13 (1874), 305-318.

[47] F. Warrain, L'œuvre philosophique d'Hoene-Wroński. Textes, commentaires et critique, 3 volumes, Les Editions Vega, Paris 1933, 1936, 1938. 